\title{
Evaluation of some flavanones as potential inhibitors for SARS-CoV-2 by molecular docking and pharmacological analysis
}

\author{
Fatma Nur Özkömeç ${ }^{1}$, Mustafa Çeşme ${ }^{2 *}$ \\ ${ }^{\mathbf{1}}$ Kahramanmaraş Sütçü İmam University, Faculty of Art and Sciences, Departmant of Biology, Kahramanmaraş, Turkey, (ORCID: 0000-0002-7789-735X), \\ fatmanurozkomec@ksu.edu.tr \\ 2*Kahramanmaraş Sütçü İmam University, Faculty of Art and Sciences, Departmant of Chemistry, Kahramanmaraş, Turkey, (ORCID: 0000-0002-2020-5965), \\ mustafacesme@msn.com
}

(First received 17 October 2021 and in final form 2 December 2021)

(DOI: 10.31590/ejosat.1010924)

ATIF/REFERENCE: Özkömeç, F. N. \& Çeşme, M. (2021). Evaluation of some flavanones as potential inhibitors for SARS-CoV-2 by molecular docking and pharmacological analysis. European Journal of Science and Technology, (31), 974-981.

\begin{abstract}
The novel coronavirus disease 2019 (COVID-19) was first described in December 2019 and then rapidly turned into a global epidemic. Although various preventive vaccines for COVID 19 disease have been developed at an astonishing pace, the lack of effective antiviral drugs against Coronavirus makes it necessary to identify therapeutic and preventive drugs. Within the scope of this study, natural plant-derived Eriodictyol, Hesperetin and Naringenin compounds were investigated by in silico methods by adopting a drug repositioning approach. In this context, the affinity of the three compounds against SARS-CoV-2 main protease was investigated by the molecular docking method, and their binding energies were calculated as $-7.3,-7.2$ and $-7.7 \mathrm{kcal} / \mathrm{mol}$, respectively. The resulting protein-flavanone compounds formed stable complex structures. In the other part of the study, these compounds' pharmacological and physicochemical properties were examined under the ADME standards, observing the Lipinski rules, and it was found that the compounds exhibited a high bioavailability profile.
\end{abstract}

Keywords: Flavanones, SARS-CoV-2, In silico, molecular docking, ADME.

\section{Moleküler kenetlenme ve farmakolojik analiz ile SARS-CoV-2 için potansiyel inhibitörler olarak bazı flavanonların değerlendirilmesi}

$\ddot{O} z$

Yeni koronavirüs hastalığı 2019 (COVID-19) ilk olarak Aralık 2019 itibariyle rapor edilmiş daha sonra hızla küresel bir salgına dönüşmüştür. COVID 19 hastalığına yönelik çeşitli önleyici aşılar şaşırtıcı bir hızla geliştirilmiş olmasına rağmen Coronavirüse karşı etkili antiviral ilaçların bulunmaması, tedavi edici ve koruyucu ilaçların tanımlanmasını zorunlu kılmaktadır. Bu çalışma kapsamında ilaç yeniden konumlandırma yaklaşımı benimsenerek doğal bitki kaynaklı olan Eriodictyol, Hesperetin and Naringenin bileşikleri in silico yöntemlerle incelenmiştir. Bu bağlamda üç bileşiğin SARS-CoV-2 main protease karş1 afinetesi moleküler docking yöntemiyle incelenmiş bağlanma enerijileri sırasıyla -7.3, -7.2 ve -7.7 kcal/mol olarak hesaplanmıştır. Oluşan protein-flavanon bileşikleri kararlı kompleks yapılar oluşturmuştur. Çalışmanın diğer bölümünde ise bu bileşiklerin farmakolojik ve fizikokimyasal özellikleri ADME standartları ölçüsünde Lipinski kuralları gözetilerek incelenmiş ve bileşiklerin yüksek biyoyararlanım profili sergilediği bulunmuştur.

Anahtar Kelimeler: Flavanonlar, SARS-CoV-2, In silico, moleküler kenetlenme, ADME.

\footnotetext{
${ }^{*}$ Corresponding Author: mustafacesme@msn.com
} 


\section{Introduction}

The novel coronavirus disease 2019 (COVID-19) was first described in China as of December 2019 and has subsequently expanded into a global outbreak leading to intense adverse and uneven social and economic desolation (Chaudhry et al., 2020). A strain of coronaviruses causes the disease called the severe acute respiratory syndrome coronavirus 2 (SARS-CoV-2). COVID-19 was characterized as a global pandemic by the World Health Organization (WHO) in March 2020 (Huang et al., 2020). The vast transmission of this virus and the uneven mortality have led to immeasurable global social and economic damage, which will take time to repair. According to the WHO, at least 240 million reported global cases and over 4.8 million globally reported Covid-19 deaths (COVID Live Update: Coronavirus - Worldometer). The vast transmission of this virus and the uneven mortality have led to immeasurable global, social, and economic damage, which will take time to repair.

Several preventative vaccines for the COVID 19 disease were developed surprisingly quickly and made accessible to the community worldwide to reduce the spread of COVID-19, displaying a profile that evokes a sense of normalcy in society. However, with the global prevalence of viral infections, the emergence of virus variants is a cause for concern and may limit vaccine efficacy. The absence of efficient antiviral drugs against Coronavirus necessitates the identification of therapeutic and preventive drugs. However, the global prevalence of viral infections and the emergence of virus variants cause concern and limit the vaccine's effectiveness.

Currently, vaccination activities continue at full speed on a global scale. The fact that no effective antiviral drugs against the Coronavirus have yet been found for nearly two years, the highly contagious nature of COVID-19, and its rapid spread have prompted researchers to work very dense to find a treatment to slow or reduce the spread of the infection. In this context, researchers have focused their attention on antiviral compounds targeting main protease, RNA polymerase, and spike glycoprotein that have been tested in in-vitro and in-vivo studies employing the concept of in silico drug repurposing.

Studies show that phytochemicals, such as phenolic acids, alkaloids, and terpenoids, have extensive antiviral properties and are widely proposed for COVID-19 therapies. Flavonoids have been proposed for use as COVID-19 therapies owing to their broad antimicrobial properties, low toxicity, antioxidant properties, and other health benefits (Azim et al., 2020; Deng et al., 2020; Kumar Verma et al., 2021). Natural plant-derived flavonoids have beneficial effects on neurodegenerative disease, type 2 diabetes, atherosclerosis, cardiovascular disease and cancer (Bora et al., 2020; Peterson, 2020). However, it is known to exert a wide variety of antiviral effects. In this context, inhibition of SARS-CoV-2 major protease (Mpro) at the active site may be a promising alternative for selective therapy design with less impact on human health. Although some studies suggest that flavonoids may inhibit the activity of this protease, the main reasons for this are the Inhibitory abilities of these natural compounds, the presence of numerous acceptors, donor, hydrophobic and aromatic functional groups that contribute to their therapeutic effects. Flavonoids, which represent a vital part of the human diet, are generally abundant in oilseeds, fruits, flowers, nuts and vegetables, increasing the ease of treatment (Aishwarya et al., 2021; Cheke, 2020; Negi et al., 2020).
In this study, natural phenolic compounds of Eriodictyol, Hesperetin, and Naringenin, belonging to the group known as flavanones (Figure 1), were investigated in silico methods for their pharmacological properties and activity against SARS$\mathrm{CoV}-2$ main protease (Mpro).
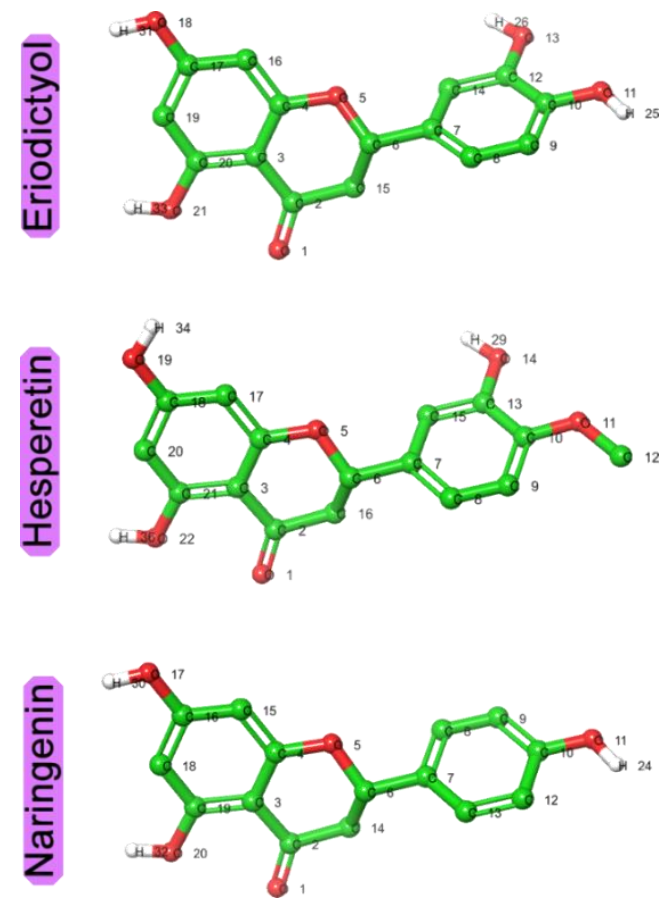

Figure 1. Chemical structures of flavanone compounds.

\section{Methods and Materials}

\subsection{Ligand Preparation}

The 2D structures of flavanones (Eriodictyol, Hesperetin, and Naringenin) were taken from PubChem and their 3D structures were minimized by Chem3D 19 using the MM2 minimization algorithm.

\subsection{Receptor Preparation}

The X-ray crystal structure of the main protease in complex with an inhibitor N3 (native ligand) (PDB code: 6LU7, $2.16 \AA$ ) was obtained from protein data bank 'PDB' (www.rcsb.org). Hetero compounds such as water, ions, and ligands in the protein structure were extracted using Discovery Studio 2020 software. The downloaded crystal structure of the protein target was converted to PDB format for the molecular docking process and saved.

\subsection{Molecular Docking Process}

In silico molecular docking studies, compounds were assessed against 6LU7, and the Vina module performed docking scoring functionality using PyRx docking software (Onur et al., 2021). The algorithm of the docking software with the optimal configuration parameters (binding modes-9, exhaustiveness-8, grid box center with $\mathrm{x}, \mathrm{y}$ and $\mathrm{z}$ coordinates of the residue location of the target protein) was used to perform dockingbased studies on the proposed inhibitor for CoV-2 protease. In the parent protease (PDB ID: 6LU7), a peptide-like co-ligand (N3 native ligand) is covalently bound with the CYS-145 receptor residue. Therefore, in docking procedures, the receptor grid of the protease was chosen by limiting it to residues occupied by the N3 ligand and interacting with the ligand 
domain. The grid at the ligand-binding site of the 6LU7 protein is centered at the binding site of $\mathrm{X}:-11, \mathrm{Y}: 14, \mathrm{Z}: 69$, and the grid dimensions are $22 \times 32 \times 32 \mathrm{~A}^{3}$. All other software parameters were set as default, and all of the ligand's bonds were permitted to rotate freely because the receptor was assumed to be rigid (Isika et al., 2020; Şahin et al., 2022). The results of the best docking poses of the interactions were analyzed in two- and three-dimensions using Discovery Studio 2020.

\subsection{Cheminformatics Studies}

The binding affinity of inhibitors to their target proteins should be examined by assessments such as the ADME analysis of the similarity of inhibitors to drugs in a biological system to check the suitability of inhibitors as potential drugs in a biological system. The inhibition properties of flavanone compounds were studied via the SWISS ADME (Daina et al., 2017) web software to identify various physicochemical descriptors and predict ADME (Adsorption, Distribution, Metabolism and Excretion) parameters. The molecules were evaluated for pharmacokinetic properties, drug-like structure, and suitability for medicinal chemistry. The pharmacokinetic properties of compounds and their suitability in a biological system were revealed using Lipinski Rule of Five (RO5) approaches (Şahin et al., 2022).

\section{Results and Discussion}

\subsection{Molecular Docking}

Repurposing and repositioning drugs and drug candidate molecules for COVID-19 have been a focus of interest among researchers working in computational chemistry and biology, especially after the onset of the coronavirus epidemic, due to the long discovery and validation periods of new drugs. At this stage, selecting target proteins and enzymes for the repurposing of drugs is an important step. Molecular docking can reveal whether the ligand/drug is docked with the receptor protein and can show the results as an array of docked complex structures with lower binding energy. This study chose the validated and highly researched main protease Mpro as the target for use against COVID-19 (Parveen \& Alnoman, 2021). Molecular docking experiments were conducted on three different compounds to identify a possible candidate for treating COVID19. This study has used the crystal structure of SARS-CoV-2 Mpro (PDB ID: 6LU7) (Figure 2) as the target receptor. SARSCoV-2 Mpro is the main protease of the new strain of 2019 coronavirus disease (Jin et al., 2020). It is a protein that intercedes the virus's replication and transcription, so the protease is often the target of the virus's potential inhibitors in drug discovery and development. This protease Mpro has a chain of 306 amino acids and involves three main domains (Kalai et al., 2021; Naveja et al., 2021). Domain I is from residues $8-101$, domain 2 is from 102 to 184 , domain III is the amino acid sequence 201 to 303 and linked to domain II by loop residues $185-200$. The substrate-binding site on this viral protein is present in a cleft between domains I and II with a Cys145His41 catalytic dyad. Main active subsites in the active Mpro site to which the substrate is attached are identified. Thus, the S1 subdomain consists of amino acids Phe140, Leu141, Asn142, His163, Glu166, and His172. The hydrophobic S2 subdomain consists of His41, Met49, Tyr54, Met165, and Asp187. The S4 binding subdomain contains amino acids Met165, Leu167, Phe185, Gln189, and Gln192 (Jin et al., 2020; Teli et al., 2021).

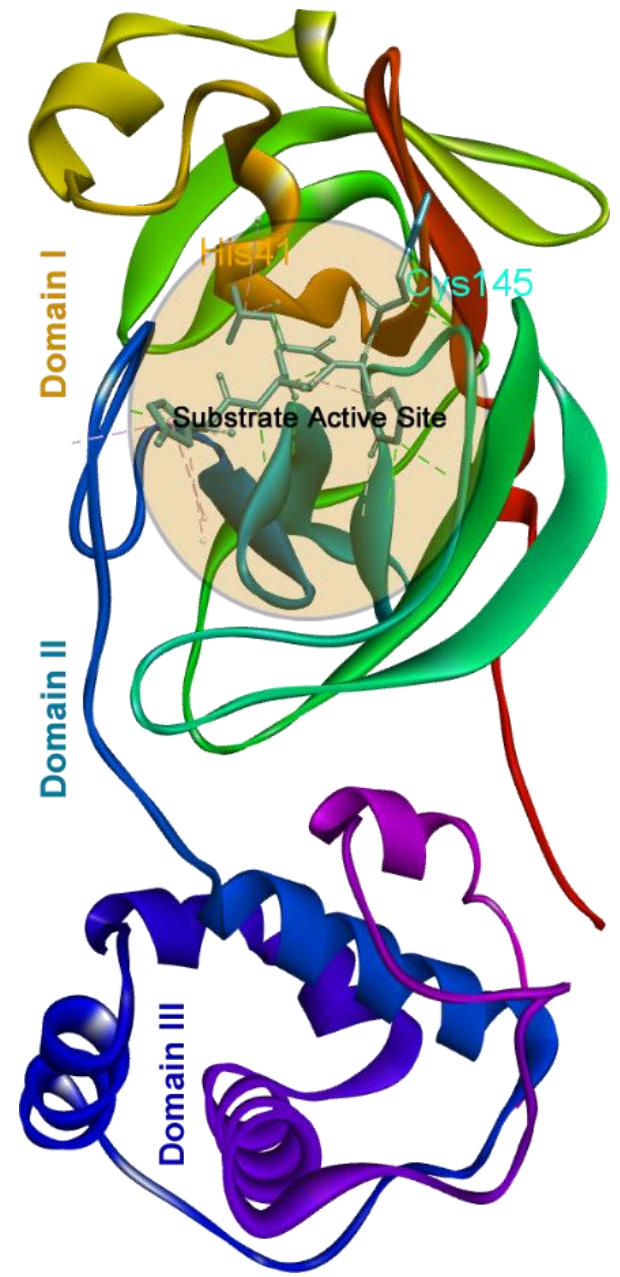

Figure 2. Crystal structure of 6LU7.

Before beginning the molecular docking procedure, it is necessary to get the electrophilic and nucleophilic sites of the ligands to make an initial estimate and understand which probable atoms or functional groups can interact with the appropriate domain or active sites protein. Calculating the molecular electrostatic potential (MEP) in drug research and development is critical for confirming molecule reactivity as inhibitors (Şahin et al., 2022). Although the molecular size and formation of the electrostatic potentials (positive, negative, and neutral) are indicated by MEP, these approaches can be an informative tool for predicting and interpreting the molecular structure of the compounds under investigation and their investigation physicochemical structure-activity relationships and properties. Furthermore, MEP is a beneficial and informative notion for predicting the reactivity of a drug to electrophilic and nucleophilic attacks. The three compounds were determined utilizing the Adaptive Poisson-Boltzmann Solvent (APBS) method and are shown in Figure 3. The rule of thumb here is that the highest negative region in the MEP is the preferred region for the electrophilic attack, shown in red while saturating the blue moieties on the map in the opposite direction. It attracts an electrophile attacking negatively charged moieties. 

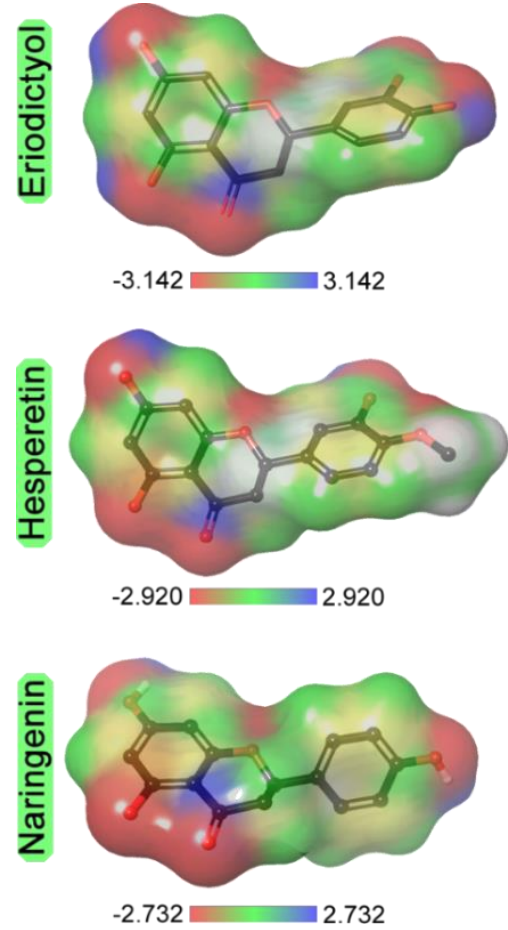

Figure 3. Molecular electrostatic potential of flavanone compounds.

This research has investigated the affinity of three molecules that belong to flavanones against 6LU7. The molecular docking results are given in Table 1 by summarizing their binding affinities and binding modes with interacting amino acids. Based on the binding interaction obtained from docking data, all molecules showed a high affinity for the active binding pocket protease, ranging from -7.2 to $-7.7 \mathrm{kcal} / \mathrm{mol}$, with the highest binding energies was found for compound Naringenin as $-7.7 \mathrm{kcal} / \mathrm{mol}$. When all protein-flavanone complexes are examined in general, it is possible to say that conventional $\mathrm{H}$ bond and hydrophobic interactions come to the fore while forming stable enzyme-compound complexes in binding the compounds to the protease's active site.

When the interaction of the Eriodictyol compound with the residues in the enzyme's active site was examined, it was observed that it made four different hydrogen bond interactions and two different pi alkyl interactions. Three of the hydrogen bonds formed were realized from the $\mathrm{H}$ atoms on the molecule to these residues with ARG188, CYS145 and LEU141. The GLU166 residue, on the other hand, interacting with the hydroxyl group oxygen connected to the double benzene ring in Eriodictyol. Two different hydrophobic pi alkyl interactions were constructed from the benzene ring to CYS145 and MET165 (Figure 4).

When the interactions between the Hesperetin compound and the protease are examined, it is seen that the H-bond interaction and hydrophobic interactions come to the fore. Accordingly, all H-bonds formed are from the Hesperetin molecule via amino acids MET165, LEU141, GLU166 and MET49. Of the hydrophobic interactions formed, pi alkyl interactions were achieved with MET165 and MET49 residues, while pi-pi T-shaped binding was achieved with HIS41 (Figure $5)$.
A
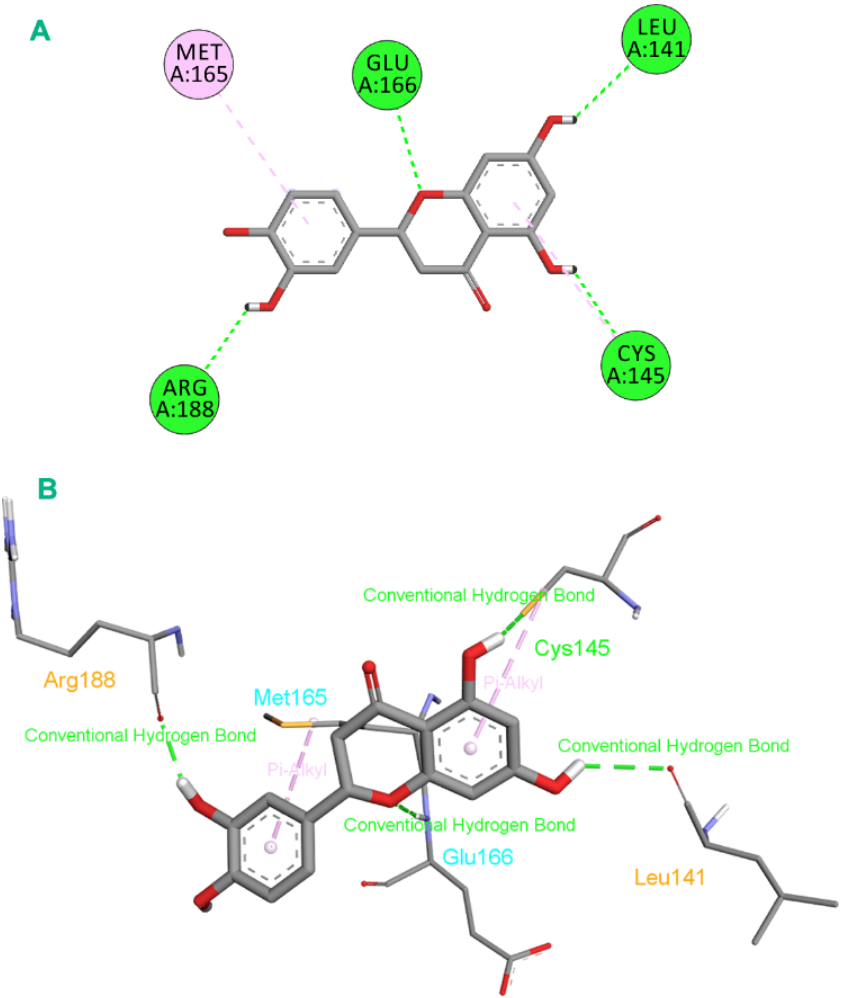

Figure 4. 2D (A) and $3 D(B)$ docked pose depiction of Eriodictyol compound.

A

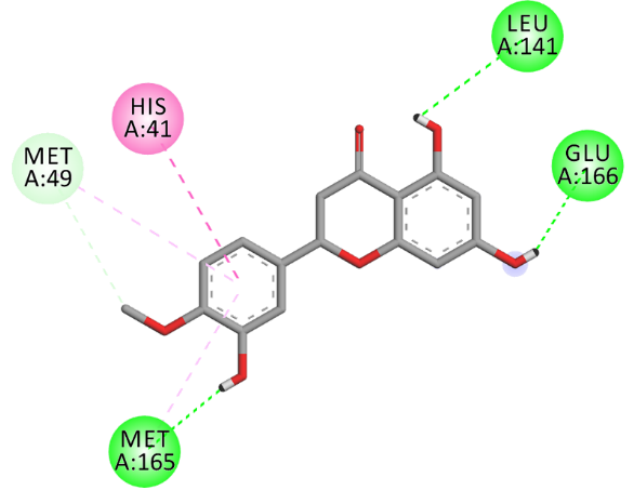

B

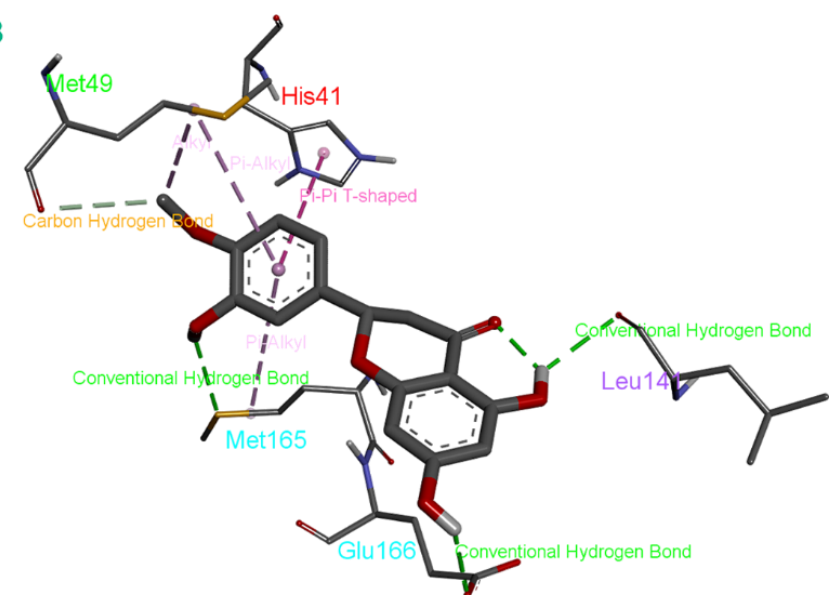

Figure 5. 2D (A) and 3D (B) docked pose depiction of Hesperetin compound.

When the complex structure of the Naringenin compound with protease is examined, it is seen that hydrogen bond interaction and hydrophobic interactions come to the fore. In addition, electrostatic-pi cation interaction occurred between the 
amino acid residue HIS163 and the benzene ring with two hydroxyl groups in the structure of Naringenin. While the $\mathrm{H}$ bonds formed were realized through LEU141 and SER144 and Naringenin, Hydrophobic alkyl interactions was observed between MET49 and Hesperetin methoxy group $\left(\mathrm{O}-\mathrm{CH}_{3}\right)$. GLY143 and GLU166 residues formed $\mathrm{H}$ bonds towards $\mathrm{O} 1$ and $\mathrm{O} 4$ atoms in the Naringenin molecule, respectively. The abundance and diversity of interactions between the Naringenin molecule and the residues in the active site played an important role in forming a stable complex structure (Figure 6).

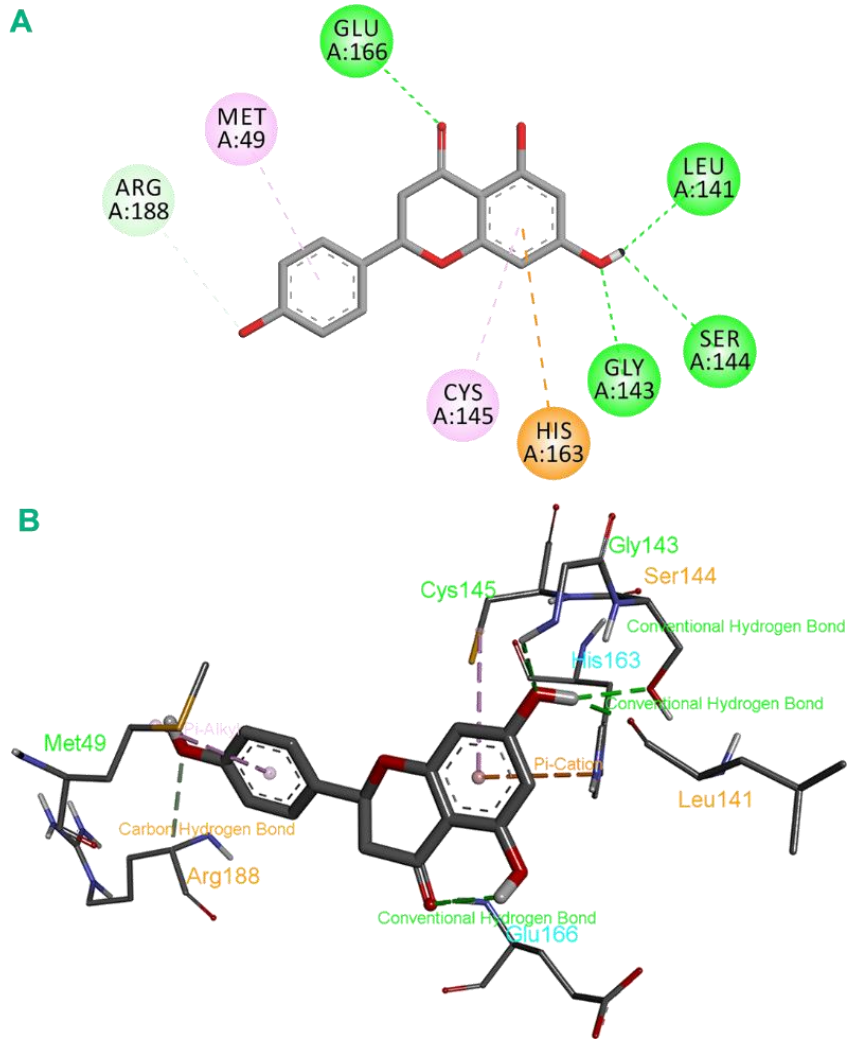

Figure 6. 2D (A) and $3 D(B)$ docked pose depiction of Naringenin compound.

Table 1. Detailed Interactions types and distances of compound-protein complexes.

\begin{tabular}{clll}
\hline Score & \multicolumn{1}{c}{ Interaction (:From-To) } & Distance $(\AA)$ & \multicolumn{1}{c}{ Bonding Types } \\
\hline \multirow{4}{*}{$-7,3$} & :Eriodictyol:H5 - A:ARG188:O & 2.00568 & H-Bond \\
& :Eriodictyol:H12 - A:CYS145:SG & 2.83967 & H-Bond \\
& :Eriodictyol:H10 - A:LEU141:O & 2.62109 & H-Bond \\
& A:GLU166:HN - :Eriodictyol:O2 & 2.44241 & H-Bond \\
& :Eriodictyol - A:CYS145 & 5.37042 & Pi-Alkyl \\
& :Eriodictyol - A:MET165 & 5.43166 & Pi-Alkyl \\
\hline \multirow{4}{*}{-7.2} & :Hesperetin:H7 - A:MET165:SD & 2.93024 & H-Bond \\
& :Hesperetin:H14 - A:LEU141:O & 2.56075 & H-Bond \\
& :Hesperetin:H12 - A:GLU166:OE1 & 2.38731 & H-Bond \\
& :Hesperetin:C9 - A:MET49:O & 3.75115 & C-H Bond \\
& A:HIS41 - :Hesperetin & 4.75631 & Pi-Pi T-shaped \\
& :Hesperetin:C9 - A:MET49 & 3.94633 & Alkyl- \\
& :Hesperetin - A:MET49 & 5.32493 & Pi-Alkyl- \\
& :Hesperetin - A:MET165 & 5.30359 & Pi-Alkyl \\
\hline \multirow{4}{*}{ :Hesperetin:H10 - A:LEU141:O } & 1.96568 & H-Bond \\
& :Naringenin:H10 - A:SER144:OG & 2.6652 & H-Bond \\
& A:GLY143:HN - :Naringenin:O4 & 2.31025 & H-Bond \\
A:GLU166:HN - :Naringenin:O1 & 2.29459 & H-Bond \\
& A:ARG188:CA - :Naringenin:O3 & 3.63977 & C-H Bond \\
& A:HIS163:NE2 - :Naringenin & 4.94769 & Pi-Cation \\
& :Naringenin - A:CYS145 & 4.90713 & Pi-Alkyl \\
:Naringenin - A:MET49 & 4.47598 & Pi-Alkyl
\end{tabular}




\subsection{In-silico ADME Findings}

The ADME data speeds up the drug discovery process by facilitating the choice and determination of the medicinal dose of molecules with an ideal safety profile in the preliminary stages of drug candidate molecules. In this way. evaluation times are accelerated in the effective drug design process. and time and valuable resources are wasted. Determination of the pharmacokinetic properties of chemical compounds or drug candidate molecules. such as absorption. distribution. metabolism. and excretion (ADME). is essential during candidate molecule identification. The rule proposed by Lipinski (RO5: rule of five) was formulated in research where the preponderance of orally administered drugs are relatively small to moderately lipophilic molecules (Alghamdi et al.. 2021; Kumar et al.. 2020). These five rules (RO5) are a practical tool that provides much information about oral activity in humans. as well as evaluating drug similarity or understanding whether a chemical compound with a particular pharmacological or biological activity has optimal chemical and physical properties. The rule's validity for a molecule is ensured if it has five or fewer hydrogen bond donors. its $\mathrm{MW}$ is below 500. the $\log \mathrm{P}$ value is below 5. and the $\mathrm{N}$ and $\mathrm{O}$ atoms are ten or less. As a result. when one or more of these rules are violated. properties such as poor absorption or permeability for chemicals and therapeutic candidates are more likely to be affected. Partition coefficient $(\log \mathrm{Po} / \mathrm{w})$. points bioavailability. water-solubility. synthetic accessibility. molecular weight. hydrogen bond properties (receiver. transmitter). rotating bonds. the number of atoms. topological polar surface area (TPSA). such as molecular properties. and rules of Lipinski are shown in Table 2 were obtained to assess the similarity of the compounds to drugs.

The Lipinski rule does not recommend more than one violation of an orally bioactive molecules. The ADME results obtained from the calculations revealed that all values obtained for compounds remained within the defined limits as specified in Lipinski's RO5 (Bharti \& Shukla. 2021; Kouznetsov. 2020). All parameters indicated in Table 2 revealed that the compounds wholly complied with the Lipinski rules and did not violate any of these rules.

For a quick assessment of drug-likeness. the bioavailability radar charts of the compounds were inspected. Lipophilicity (LIPO). size (SIZE). polarity (POLAR). solubility (INSOLU). flexibility (FLEX), and saturation (INSATU) are the six physicochemical factors identified in this radar plot. Radar chart plot range is displayed as a pink area on each axis. created by default with identifiers adapted from SwissADME; the colored pink area in this radar plot specifies the boundaries of these descriptors. and a compound must fall within the radar plot to be deemed genuinely drug-like (pink hexagon). The bioavailability radar charts show that all synthetic compounds have a high oral bioavailability profile. consistent with this concept (Figure 7).

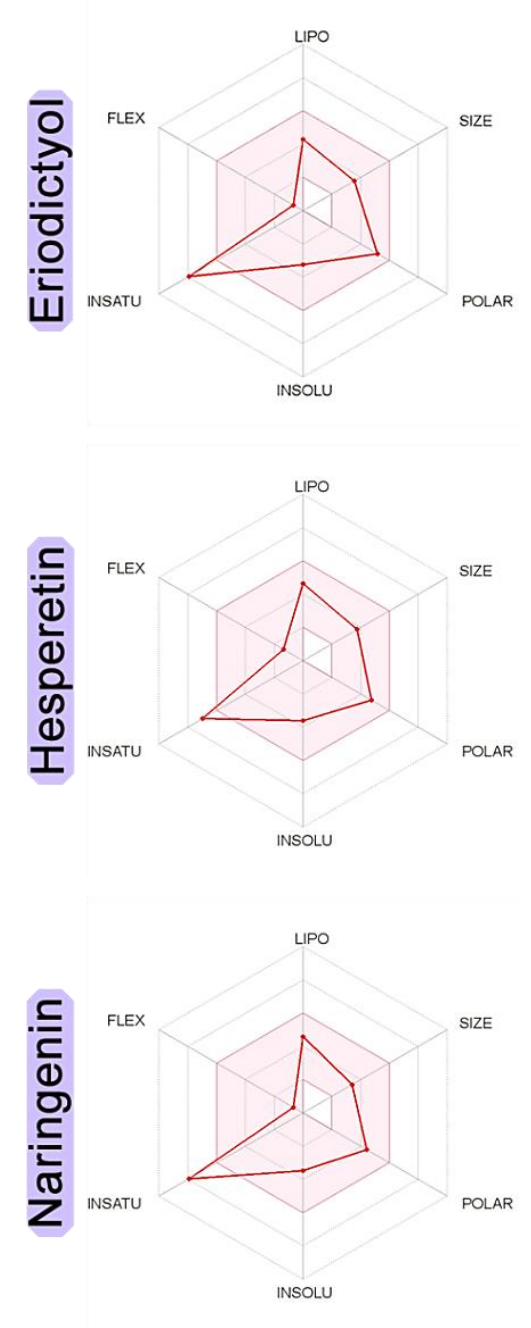

Figure 7. Bioavailability radar related to physicochemical properties of molecules.

Table 2. Physicochemical and pharmacological features of compounds

\begin{tabular}{|c|c|c|c|c|c|c|c|c|c|c|c|c|}
\hline & MW & GI Abs & BBB & $\operatorname{TPSA}\left(\AA^{2}\right)$ & RB & HBA & HBD & $\log P o / w$ & $\mathbf{L V}$ & BS & SA & WS \\
\hline & \multicolumn{12}{|c|}{ Rules } \\
\hline Comp. & $<500$ & - & - & $<130$ & $\leq 9$ & $\leq 10$ & $\leq 5$ & $\leq 5$ & $\leq 1$ & - & - & - \\
\hline Eriodictyol & 288.25 & High & No & 107.22 & 1 & 6 & 4 & 1.45 & 0 & 0.55 & 3.11 & -3.26 \\
\hline Hesperetin & 302.28 & High & No & 96.22 & 1 & 6 & 3 & 1.91 & 0 & 0.55 & 3.22 & -3.62 \\
\hline Naringenin & 272.25 & High & No & 86.99 & 1 & 5 & 3 & 1.84 & 0 & 0.55 & 3.01 & -3.49 \\
\hline
\end{tabular}

Key: MW: Molecular weight (gr/mol). GI Abs: Gastrointestinal absorption. BBB: Blood brain barrier permeant TPSA: Topological polar surface area.

RB: number of rotatable bonds. HBA: number of hydrogen bond acceptors. HBD: number of hydrogen bond donors. LV: number of Lipinski rule of 5 violations. Log Po/w (iLOGP): Lipophilicity . BS: Bioavailability score. SA: Synthetic accessibility [From 1 (very easy) to 10 (very difficult)]. WS: Water solubility. Log $S$ (Insoluable $<-10<$ Poorly $<-6<$ Moderately $<-4<$ Soluable $<-2$ Very $<0<$ Highly) 


\section{Conclusions and Recommendations}

So far. no drug has been commercially available for the treatment and prevention of COVID-19. This study aimed to examine various medicinal plant-derived compounds that can be used to inhibit the COVID-19 infection pathway. In this context. the activity of Eriodictyol. Hesperetin and Naringenin compounds. which are members of the flavanone family. against SARS-CoV-2 main protease was investigated by molecular docking method. Molecular docking results revealed that all three compounds formed stable complex structures with the target protein. In addition to molecular docking studies. the pharmacological properties of the compounds were also studied in detail. The ADME data obtained for all three compounds were within the prescribed limits and no Lipinski rule was violated. However. more research is needed to examine and explore the potential uses of these compounds as drugs.

\section{References}

Aishwarya, S., Gunasekaran, K., Sagaya Jansi, R., \& Sangeetha, G. (2021). From genomes to molecular dynamics - A bottom up approach in extrication of SARS CoV-2 main protease inhibitors. Computational Toxicology, 18(December 2020), 100156. https://doi.org/10.1016/j.comtox.2021.100156

Alghamdi, H. A., Attique, S. A., Yan, W., Arooj, A., Albulym, O., Zhu, D., Bilal, M., \& Nawaz, M. Z. (2021). Repurposing the inhibitors of COVID-19 key proteins through molecular docking approach. Process Biochemistry, 110(May), 216222. https://doi.org/10.1016/j.procbio.2021.08.015

Azim, K. F., Ahmed, S. R., Banik, A., Khan, M. M. R., Deb, A., \& Somana, S. R. (2020). Screening and druggability analysis of some plant metabolites against SARS-CoV-2: An integrative computational approach. Informatics in Medicine Unlocked, 20 ,

100367. https://doi.org/10.1016/j.imu.2020.100367

Bharti, R., \& Shukla, S. K. (2021). Molecules against COVID19: An in Silico Approach for Drug Development. Journal of Electronic Science and Technology, 19(1), 14-24. https://doi.org/10.1016/j.jnlest.2021.100095

Bora, A., Pacureanu, L., \& Crisan, L. (2020). In Silico Study of Some Natural Flavonoids as Potential Agents against COVID-19: Preliminary Results. Chemistry Proceedings, 3(1), 25. https://doi.org/10.3390/ecsoc-24-08343

Chaudhry, S. N., Hazafa, A., Mumtaz, M., Kalsoom, U., Abbas, S., Kainaat, A., Bilal, S., Zafar, N., Siddique, A., \& Zafar, A. (2020). New insights on possible vaccine development against SARS-CoV-2. Life Sciences, 260, 118421. https://doi.org/10.1016/j.lfs.2020.118421

Cheke, R. S. (2020). The Molecular Docking Study of Potential Drug Candidates Showing Anti-COVID-19 Activity by Exploring of Therapeutic Targets of SARS-CoV-2. Eurasian Journal of Medicine and Oncology, 4(3), 185-195. https://doi.org/10.14744/ejmo.2020.31503

COVID Live Update: Coronavirus - Worldometer. Retrieved October 15, 2021, from https://www.worldometers.info/coronavirus/

Daina, A., Michielin, O., \& Zoete, V. (2017). SwissADME: A free web tool to evaluate pharmacokinetics, drug-likeness and medicinal chemistry friendliness of small molecules. Scientific Reports, $\quad 7(1), \quad 1-13$. https://doi.org/10.1038/srep42717
Deng, J., Hou, X., Zhang, T., Bai, G., Hao, E., Chu, J. J. H., Wattanathorn, J., Sirisa-ard, P., Soo Ee, C., Low, J., \& Liu, C. (2020). Carry forward advantages of traditional medicines in prevention and control of outbreak of COVID19 pandemic. Chinese Herbal Medicines, 12(3), 207-213. https://doi.org/10.1016/j.chmed.2020.05.003

Huang, F., Li, Y., Leung, E. L. H., Liu, X., Liu, K., Wang, Q., Lan, Y., Li, X., Yu, H., Cui, L., Luo, H., \& Luo, L. (2020). A review of therapeutic agents and Chinese herbal medicines against SARS-COV-2 (COVID-19). Pharmacological Research, 158(April), 104929. https://doi.org/10.1016/j.phrs.2020.104929

Isika, D., Çeşme, M., Osonga, F. J., \& Sadik, O. A. (2020). Novel quercetin and apigenin-acetamide derivatives: Design, synthesis, characterization, biological evaluation and molecular docking studies. RSC Advances, 10(42), 25046-25058. https://doi.org/10.1039/d0ra04559d

Jin, Z., Du, X., Xu, Y., Deng, Y., Liu, M., Zhao, Y., Zhang, B., Li, X., Zhang, L., Peng, C., Duan, Y., Yu, J., Wang, L., Yang, K., Liu, F., Jiang, R., Yang, X. X. X. X., You, T., Liu, X. X. X. X., ... Yang, H. (2020). Structure of Mpro from SARSCoV-2 and discovery of its inhibitors. Nature, 582(7811), 289-293. https://doi.org/10.1038/s41586-020-2223-y

Kalai, F. El, Çınar, E. B., Lai, C. H., Daoui, S., Chelfi, T., Allali, M., Dege, N., Karrouchi, K., \& Benchat, N. (2021). Synthesis, spectroscopy, crystal structure, TGA/DTA study, DFT and molecular docking investigations of (E)-4-(4methylbenzyl)-6-styrylpyridazin-3(2H)-one. Journal of Molecular $\quad$ Structure, $\quad 1228, \quad 129435$. https://doi.org/10.1016/j.molstruc.2020.129435

Kouznetsov, V. V. (2020). COVID-19 treatment: Much research and testing, but far, few magic bullets against SARS-CoV-2 coronavirus. In European Journal of Medicinal Chemistry (Vol. 203). Elsevier Masson SAS. https://doi.org/10.1016/j.ejmech.2020.112647

Kumar, A., Choudhir, G., Shukla, S. K., Sharma, M., Tyagi, P., Bhushan, A., \& Rathore, M. (2020). Identification of phytochemical inhibitors against main protease of COVID19 using molecular modeling approaches. Journal of Biomolecular Structure and Dynamics, $0(0), 1-11$. https://doi.org/10.1080/07391102.2020.1772112

Kumar Verma, A., Kumar, V., Singh, S., Goswami, B. C., Camps, I., Sekar, A., Yoon, S., \& Lee, K. W. (2021). Repurposing potential of Ayurvedic medicinal plants derived active principles against SARS-CoV-2 associated target proteins revealed by molecular docking, molecular dynamics and MM-PBSA studies. Biomedicine and Pharmacotherapy, 137, 111356. https://doi.org/10.1016/j.biopha.2021.111356

Naveja, J. J., Madariaga-Mazón, A., Flores-Murrieta, F., Granados-Montiel, J., Maradiaga-Ceceña, M., Alaniz, V. D., Maldonado-Rodriguez, M., García-Morales, J., SenosiainPeláez, J. P., \& Martinez-Mayorga, K. (2021). Union is strength: antiviral and anti-inflammatory drugs for COVID19. Drug Discovery Today, 26(1), 229-239. https://doi.org/10.1016/j.drudis.2020.10.018

Negi, M., Chawla, P. A., Faruk, A., \& Chawla, V. (2020). Role of heterocyclic compounds in SARS and SARS CoV-2 pandemic. Bioorganic Chemistry, 104(August), 104315. https://doi.org/10.1016/j.bioorg.2020.104315

Onur, S., Çeşme, M., Köse, M., \& Tümer, F. (2021). New iminomethoxy derivatives: design, synthesis, characterization, antimicrobial activity, DNA interaction and molecular 
docking studies. Journal of Biomolecular Structure and Dynamics,

$O(0)$,

$1-13$. https://doi.org/10.1080/07391102.2021.1955741

Parveen, S., \& Alnoman, R. B. (2021). Potential exploration of recent FDA-approved anticancer drugs against models of SARS-CoV-2's main protease and spike glycoprotein: A computational study. Biointerface Research in Applied Chemistry, 11(3),

10059-10073. https://doi.org/10.33263/BRIAC113.1005910073

Peterson, L. (2020). COVID-19 and Flavonoids: In Silico Molecular Dynamics Docking to the Active Catalytic Site of SARS-CoV and SARS-CoV-2 Main Protease. SSRN Electronic https://doi.org/10.2139/ssrn.3599426

Şahin, İ., Çeşme, M., Özgeriş, F. B., Güngör, Ö., \& Tümer, F. (2022). Design and synthesis of 1,4-disubstituted 1,2,3triazoles: Biological evaluation, in silico molecular docking and ADME screening. Journal of Molecular Structure, 1247 , 131344. https://doi.org/10.1016/j.molstruc.2021.131344

Teli, D. M., Shah, M. B., \& Chhabria, M. T. (2021). In silico Screening of Natural Compounds as Potential Inhibitors of SARS-CoV-2 Main Protease and Spike RBD: Targets for COVID-19. Frontiers in Molecular Biosciences, 7(January), 599079. https://doi.org/10.3389/fmolb.2020.599079 